\title{
Trading Companies
}

\author{
Arnold Wald \\ Advogado; Professor \\ universitário (UEG)
}

\begin{abstract}
"...vamos realmente criar uma companhia de comércio com vendedores locais, vamos produzir um catálogo e sair vendendo de porta em porta os nossos produtos, que é a única forma de se conseguir vender. Ninguém vende sentado no escritório".
\end{abstract}

Ministro Delfim Neto

Nos últimos meses, o grande público tem acompanhado a entrada na moda de uma nova estrutura empresarial, cujo sentido ainda não ficou muito claro para os leigos - as Trading Companies. $A$ elas se referem os estudos especializados, as notícias de imprensa, as reuniões de associações de classe e os seminários de do orda ordem. Já agora estamos com uma regulamentação própria esperança de rápido e intenso desenvolvimento.

Efetivamente, quando foi lançado há alguns anos atrás o slogan EXPORTAR É A SOLUÇÃO, muitos não imaginavam que se iniciava uma nova fase do milagre brasileiro e que o Governo apresentava não apenas uma idéia programática ou uma frase literária, mas sim uma tática agressiva e eficaz de crescimento da economia nacional. Dentro da filosofia da política de exportação, tivemos uma primeira fase baseada nos incentivos fiscais e, agora, passamos a uma nova etapa caracterizada pela criação das Trading cialização integrada. Não há dúvida que as estatísticas revelam a existência de
um incontestável paralelismo entre o crescimento do produto in- 
terno bruto dos países em vias de desenvolvimento e a evolução de suas exportações. Na realidade, o aumento das exportações, especialmente de produtos manufaturados, é uma garantia do crescimento da economia nacional, pois além de assegurar as divisas necessárias para a realização das importações de bens, serviços e know-how indispensáveis ao desenvolvimento, permite uma melhcr utilização dos vários fatores de produção. Evita-se, assim, que a reduzida capacidade de importar - decorrente de falta de divisas - possa constituir entrave ao crescimento do País, como já aconteceu em determinadas fases da nossa história, Os meios de garantir o equilíbrio do balanço de pagamento diante da necessidade de importar consistem no recebimento de investimentos, nos empréstimos externos e nas exportações. Estas últimas se revestem da maior importância, pois levam à ampliação do mercado produtor, aumentando o número de empregos e introduzindo a utilização de técnicas e escalas mais adequadas. Conseqüentemente, os produtos melhoram em qualidade e podem baixar em preço. Assim, a pressão em favor da exportação passa a constituir um fator de racionalização industrial e até de combate à inflação no plano interno.

A política de exportação, fixada após a Revolução de 1964, teve assim metas altamente válidas que foram alcançadas graças à política de incentivos fiscais, consagrada no plano federal e, já agora, acatada pelos Estados, nos termos dos convênios. Verificou-se, assim, em dez anos, um incontestável aumento das exportações, especialmente no tocante aos produtos acabados e semiacabados, abrindo novas áreas de expansão para a nossa indústria e obrigando-a a uma revisão e reciclagem para o atendimento das exigências do mercado externo. Pôde, pois, o Brasil aumentar progressivamente a sua participação no campo internacional como produtor de manufaturados.

As principais dificuldades encontradas pelos industriais brasileiros foram referentes ao controle de qualidade e à falta de dimensões para atender aos pedidos internacionais, ao mesmo tempo que se sentia a necessidade de uma estrutura adequada para abrir o mercado externo aos produtos brasileiros, sem que as nossas empresas, geralmente de tamanho pequeno ou médio, tivessem condições econômicas para criar e suportar tal estrutura, que é todavia indispensável no comércio internacional.

Com o decorrer do tempo, os exportadores brasileiros utilizaram substancialmente os incentivos fiscais, os financiamentos governamentais e o seguro de crédito e, em virtude deles, nume- 
rosas empresas fizeram conversões necessárias para poder atender as encomendas oriundas do exterior. Aos poucos, fomos verificando o espírito relativamente estático e a ausência de grandes perspectivas da ALALC, enquanto no mercado internacional, encontramos dificuldades para competir com os grandes exportadores, como o Japão e a Alemanha, especialmente depois da tentativa de volta dos Estados Unidos ao protecionismo.

Examinando as exportações brasileiras, verificamos que um reduzido número de produtos representava a maior parte da mercadoria remetida para o exterior e algumas poucas empresas conCentravam a maior parte do volume das nossas exportações. Evidencia-se que numerosas sociedades comerciais brasileiras têm preço e qualidade para entrar no mercado externo, mas não estão em condiçöes de competir com empresas de outros países no campo dos canais de comercialização, que somente se tornam acessíveis para exportadores que representem um grande volume escala.

só A existência de uma rede de comercialização internacional minim justifica e somente se compreende a partir de um limite duto no de exportações, que constitui o piso para a entrada do procomero mercado internacional. Por outro lado, as despesas de das; maior o volume, menor proporcionalmente torna-se o custo comercialização.

leiras Considerando que as dimensões atuais das empresas brasitrang são geralmente muito inferiores às de suas congêneres esnais ou multí se afirmou que as grandes companhias internaciocado ox multinacionais, que são as maiores vendedoras no mertores industriais brasileiros.

dustrissim, à política interna de concentração comercial e inlo Governotificada pelas fusões e incorporações incentivadas pefiscal, Gerno com uma legislação especial e vantagens de ordem uma es deveria corresponder, no plano da política de exportação, nomia estrutura que garantisse a utilização das vantagens da ecores brasilescala, para permitir a competitividade dos exportadorealizasileiros no campo internacional. Uma primeira tentativa foi todavada com a organização dos consórcios de exportadores, que, indispa, não reuniram o capital necessário, nem apresentaram a dispensável agressividade para consolidar a nossa posição no 
mercado internacional. Assim, uma nova fase se inicia com a organização das Trading Companies, inspiradas no exemplo japonês, que oferecem, às pequenas e médias empresas, os meios necessários para padronizar, racionalizar, financiar e promover as suas exportações.

Diante de um mundo cada dia mais complexo e de uma divisão progressivamente maior de funções e tarefas, a exportação passou a ser uma atividade especializada e exige instrumentos próprios de trabalho e equipamento adequado. Ocorre assim uma substituição de atividade. Do mesmo modo que, nas relações internas, o revendedor deixou de financiar o adquirente do automóvel ou de aparelhos eletrodomésticos para atribuir tal função à financeira, mediante a utilização da alienação fiduciária, no campo internacional, o industrial produz para que a Trading Company faça as suas exportações. Mas, não se pretende, com as novas medidas, impedir que os exportadores tradicionais continuem a realizar tal função. Ao contrário. pensa-se em ampliar o front da exportação, acrescentando aos que exportam diretamente, porque têm condições de fazê-lo, aqueles que não poderiam realizar a exportação direta, mas que poderão fazê-la através da Trading Company, cujos serviços de marketing, informação, financiamento, transporte e garantias poderão utilizar.

Não se trata, pois, de substituir uma técnica antiga por outra nova, mas sim de criar um novo instrumento que permita a exportação para aqueles que, pelos meios tradicionais, estavam inabilitados a fazê-la por uma desproporção entre suas dimensões e as necessidades do mercado internacional.

Enquanto historicamente a especialização se fazia por produtos, atualmente a divisão do trabalho não depende mais dos produtos, em virtude de uma diversificação fecunda, mas sim da função exercida. Assim sendo a Trading Company surge, como órgão auxiliar do industrial, para permitir que penetre e se conso. lide no esotérico e cada vez mais complexo mercado internacional.

Partindo da idéia de ser o comércio exterior, no seu desen volvimento, uma técnica de mobilização integral dos recursos hư manos e materiais internos, que acaba aumentando o nível de produção econômica do País, o problema básico passa a consistir no exame dos instrumentos válidos e adequados para incrementar as exportações. Não há dúvida que a primeira condição, necessá, ria, mas não suficiente, consiste em ter o que exportar, em preço e qualidade competitivos no mercado internacional. Mas, a exis R. Serv. públ., Brasillia, 109 (1) jan./mar. 1974 
tência da produção, por si só, não é suficiente numa época de grande sofisticação e a segunda fase de grande importância consiste na comercialização que, no campo internacional, se reveste de incontestáveis e variadas peculiaridades.

Como assinalava, em recente estudo o eminente Presidente do Banco Central e ilustre economista pátrio Dr. ERNANE GALVEAS, há uma premente necessidade de inovar para poder conquistar os grandes mercados externos, acrescentando que "a essência da comercialização inovadora está em descobrir novos mercados para produtos tradicionais, encontrar mais eficientes métodos de transporte. acondicionamento, estocagem e venda, buscar influência sobre os produtos visando a melhoria dos tradicionais e a introdução de novos produtos, e prover condutos estabilizadores das vendas aptos a incentivar a realização de investimentos tendentes à produção em massa, onde tal escala de operação contribua para redução dos custos unitários".

histo GABRAITH salientou oportunamente que na atual fase da história mundial o produtor e/ou o exportador condicionam o consumidor em vez de atenderem as necessidades normais e naturais do cliente. Este condicionamento implica em dar maior ênfase nas exportações ao marketing e à publicidade.

A inovação e a utilização de técnicas de comercialização, que se apresentam com relativa simplicidade para as matériasprimas e os produtos agrícolas, vão adquirindo um caráter de complexidade e sofisticação crescentes quando se trata de bens de consumo duráveis e finalmente de equipamentos, exigindo pois do produtor-exportador importantes providências no tocante à estocagem, ao transporte, estudos de mercado e de financiamentos, utilização das mais variadas formas de crédito e complementação de uma operação pela outra (package deal - operação pacote ou turn key job abrangendo simultaneamente venda de equipamento, prestação de serviços e financiamento com a entrega ao comprador das chaves da fábrica já pronta e em condições de imediato funcionamento), a fim de conseguir, pela diversificação, custos mais baixos e, conseqüentemente, melhores preços, com condições de competição na área internacional.

der Diante da impossibilidade financeira do produtor de atencompas novos requisitos da competição internacional, surgiram as lidadenhias gerais de comércio ou trading companies, com a finares, de assessorar e complementar as atividades dos produtoes, tornando-se as grandes catalizadoras das transações, as fi- 
nanciadoras parciais ou totais, por conta própria ou de terceiro, as organizadoras do transporte e do armazenamento e as criadoras de um fluxo contínuo de informações e de estudos de marketing para o cliente. Trata-se, pois, de uma assessoria ou de uma representação integrada, abrangendo todos os aspectos do negócio, desde a parte de estudos até a realização e execução dos contratos, incluindo, pois, aspectos financeiros, técnicos econômicos, jurídicos e fiscais.

Com a evolução tecnológica, a exportação direta vai se tornando mais rara e empresas especializadas passam a cuidar da venda no exterior e da exportação dos produtos nacionais. Trata-se de órgãos muito flexíveis e cuja função pode estender-se ou redudzir-se, num leque que se coaduna com as necessidades do cliente e as exigências do mercado. Assim, conforme o caso, a trading funciona no contrato de venda em nome próprio ou como representante e procuradora do produtor, ou ainda como avalista ou até como simples corretora que aproximou as partes.

O financiamento é função fundamental da trading especialmente numa fase na qual falta normalmente ao exportador o capital de giro necessário para poder competir no mercado interna. cional. Ainda aqui, a companhia de comércio não se limita a utilizar recursos próprios, pois incumbe-se de estudar e realizar a engenharia financeira da operação, mobilizando financiamentos privados e públicos, no País ou no exterior, para assegurar a rentabilidade da operação. A sua atuação financeira vai desde o desconto de títulos vinculados à exportação até o pagamento antecipado da mercadoria e a concessão de meios para a aquisição do equipamento necessário ou útil à produção.

Os problemas de armazenamento e de transporte, com a utilização das formas mais racionais e menos onerosas, são também da competência normal da trading, que procura colocar o excesso de produção, funcionando como órgão regularizador do mercado e consegue o pleno emprego, utilizando navios especiais $e$ de grande tonelagem e casando as operações de importação e exportação, a fim de evitar a existência de qualquer capacidade ociosa no transporte.

O marketing realizado pelas trading companies abrange não somente o estudo do mercado, mas ainda o das técnicas de vendas e as alternativas dos canais de produção, fazendo com que o pro. dutor atenda, na fabricação dos equipamentos exportados, às peculiaridades e necessidades dos consumidores de cada localida- 
de. O estudo das legislações locais, a fixação dos preços e da respectiva política e a organização das promoções, também constituem matéria da responsabilidade das companhias de comércio, que estudam pois todos os elementos favoráveis à realização do negócio, desde os incentivos fiscais até a melhor adaptação do produto ao gosto do cliente usuário final.

As tradings ainda realizam, por iniciativa própria ou para atender a pedidos de produtores ou de consumidores, promoçöes de importação ou exportação. Dedicam-se, por exemplo, à venda de fábricas inteiras que exportam e montam para entregá-las em condições de imediato funcionamento (turn key job). Trata-se de operação interessante especialmente quando há urgência em assegurar o início da produção de um artigo ou a realização de obras prioritárias. Os corredores de exportação tiveram a sua primeira fase de execução contratada pelo Governo brasileiro com 2s trading companies japonesas mediante este tipo de operação. Por outro lado, organizam a importação de matéria-prima para a indústria local, realizando, muitas vezes, joint ventures, ou seja, sociedades em conta de participação para um negócio determido, com o importador ou exportador e associando-se a empresas locais em cujo capital aceitam uma participação acionária.

Finalmente, a trading se destina a transferir conhecimentos tecnológicos e a organizar investimentos tanto no mercado interno como no exterior. É, em certo sentido, uma espécie de ponte entre o mercado interno e o mundo internacional, fazendo com que se dê acesso e condições de vendas às pequenas e médias empresas nos contratos internacionais, que normalmente se caracterizam pelo seu gigantismo.

$\mathrm{Na}$ área interna, o crédito permite que o consumidor possa adquirir hoje aquilo que, sem financiamento, somente num futuro remoto poderia comprar. No campo internacional, a trading company, como catalizadora de negócios, admite que possam realizar transações internacionais, por seu intermédio, empresas que, pela Sua natureza e dimensões, normalmente, no momento, não teriam Condições para tanto, por faltar-lhes os adequados instrumentos de comercialização, embora oferecessem artigos com preço e qualidade competitivos.

Num mundo em que os serviços se tornam cada dia mais importantes e no qual se destaca a relevância crescente do know-
how em todos os seus sentidos, a trading company é, incontestavelmente, um grande agente do progresso econômico, desde que the sejam garantidas condições adequadas de funcionamento. 
Não se pode cogitar de trading company sem evocar o exemplo japonês das sogo shosha ou companhias gerais de comércio, (sogo: geral - sho : comércio - sha : companhia). Já se afirmou que não há como definir as tradings japonesas, pois têm elas um significado experimental. Na realidade, se elas não existissem, ninguém poderia inventá-las e elas representam uma realidade histórica, que tem acompanhado as vicissitudes e as euforias da economia japonesa, inscrevendo, na sua vivência, as várias fases do desenvolvimento do País.

Já sabemos que são empresas gigantescas que, ultrapassando os simples ramos da exportação e da importação, tornaramse organizadoras e realizadoras de negócios, no campo interno e internacional, dominando, na realidade, a produção e a distribuição da maioria dos artigos de equipamento e de consumo. Apresentam-se, assim, com traços muito diversos, das firmas importadoras e exportadoras existentes no resto do mundo.

Se se perguntar a um funcionário governamental nipônico quantas trading firms existem no Japão, deverá afirmar que são 6.200 , conforme se verifica pelas estatísticas. Se a indagação for feita a um homem de negócios, dirá que são 12 ou 13 que são as empresas nas quals se concentra o grande movimento comercial do pais. Finalmente, se formos saber da posição existente na matéria no Japão conversando com o empregado de uma trading firm japonesa, responderá que só há uma - e na qual ele trabalha. $\mathrm{Na}$ realidade, a referência a seis mil empresas é exagerada, pois dois terços das mesmas têm um movimento de menos de US\$ 12.000.000,00 por ano. Cerca de duas mil representam as empresas médias com um movimento que alcança US $\$ 12.000 .000,00$ anualmente. Em seguida, encontramos os doze grandes com negócios superiores a trezentos milhões de dólares por ano cada uma.

As doze grandes trading companies representam no Japão cerca de $60 \%$ das exportacões e $70 \%$ das importações do país, além de $25 \%$ do comércio interno por atacado. Essa concentraçăo é única no mundo, pois, mesmo nos países de economia socialista, inexistem organizações que tenham tal diversificação de mercadorias e equipamentos, alcançando as dimensões das companhias japonesas. O que as caracteriza é a não especialização, abrangendo as suas atividades as mais diversas formas de negócios e os objetos os mais distintos. Contando o seu catálogo de vendas com mais de 10.000 artigos, as trading realizam operações que cobrem todo o comércio "desde os mísseis até o ta- 
Iharim chinês", de acordo com o ditado. Negociam, pois, com maquinaria de toda espécie, aviões, navios, produtos de aço, óleo, carvão, madeira serrada, tecidos, sal, brinquedos, café, chá preto, açúcar, câmaras, enlatados, relógios etc.... Na realidade, não se limitam à atividade comercial, mas organizam e lideram indústrias, garantem a conservação e manutenção do material e equipamentos vendidos, constroem, funcionam como corretores, agentes de seguros, organizadores de transporte e de supermercados.

Vinculados aos bancos, funcionam em certo sentido como entidades complementares do sistema financeiro, realizando operações que caracterizariam o banco de investimento ou a banque d'affaire. A trading pertence a um grupo de empresas que coordena e cujo desenvolvimento integrado lidera. E uma frente avançada do grupo econômico, que serve como ponte para os noVos negócios, interna e externamente, realizando associações, tomando participações acionárias, fazendo investimentos e contratando negócios comuns sob as diversas formas de joint venture.

Com um pessoal altamente treinado, contando com recurSos financeiros muito importantes e drenando negócios novos para o Japão e negócios japoneses para o exterior, as tradings constituiram o que elas denominam "as auto-estradas comerciais púprodutos, nos vários sentídos, permitindo uma distribuição a custo baixo, enquanto as "rotas privadas" são utilizadas por uma variedade limitada de artigos, sendo mais restritas, menos conservadas e mais onerosas.

A generalização da atividade e a presença em todos os mercados mundiais, a informação contínua e sempre mantida em dia e a concentração de recursos fazem da trading um grande cataliSador de negócios com a possibilidade de oferecer condições especiais em virtude de suas próprias dimensões e da complementação que pode realizar entre negócios diferentes.

Trata-se de empresas com cerca de dez mil empregados, contando com uma centena de escritórios no exterior e cerca de quarenta no próprio Japão. Encontramos as suas filiais e representações nos grandes centros do mercado mundial, em Nova lorque, Londres, Paris, Milão, Dusseldorf, Amsterdam e até Moscou. A sua maior força de influência se exerce no Sudeste da Ásia, nas Filipinas, na Malásia, Coréia, Tailândia, Indonésia e India. Ultimamente, as tradings japonesas sofreram um grande desenvolvimento na Austrália. 
$\mathrm{Na}$ realidade, coube às tradings fazer com que o Japão pudesse recuperar o tempo perdido com a sua entrada tardia na fase do capitalismo industrial. Após a Segunda Guerra Mundial, quando os grandes conglomerados patriarcais (zaibatsu) foram dissolvidos, desmembrando-se em menores unidades produtoras $\epsilon$ comerciais, houve uma reformulação das empresas locais. Com o rápido avanço tecnológico, surgiram importantes indústrias que adquiriram fama internacional, mas a sua tendência, por motivos de ordem tradicional e da própria mentalidade japonesa de dividir o trabalho, foi no sentido de concentrar a sua atividade no campo da produção, usando as tradings como ponte para o mercado externo e como instrumento de comercialização, garantindo ao industrial a matéria-prima e escoando os seus produtos manufaturados. Aos poucos, com a necessidade de maior capital para aumentar as instalações das fábricas e atender ao capital de giro, trading companies e bancos foram financiando as indústrias e investindo nas mesmas, adquirindo participações acionárias que foram aumentando com o tempo. Por sua vez, os industriais, algumas vezes, investiram a sua poupança nas trading companies, criando, assim, um intrincado entrosamento de participações que caracteriza o mundo dos negócios no Japão.

Os grandes grupos japoneses que contam todos com as suas trading firms lideram assim um conjunto de cerca de trinta empresas, tendo como órgão financeiro central um banco. A diversificação das companhias fez com que se dissesse que um empregado da Mitsubishi pode dirigir um carro Mitsubishi, viajar num ônibus feito pela companhia, comprar gasolina num posto da mesma empresa, beber cerveja fabricada pelo grupo e usar roupa feita com fibras sintéticas da Mitsubishi, cuja matéria-prima entrou no Japão em navio construído pela companhia com aço de suas empresas. A trading Mitsubishi Shoji atende à totalidade do grupo, realizando cerca de $30 \%$ dos seus negócios com produtos das empresas Mitsubishi e cabendo-lhe negociar $35 \%$ da produção do grupo, o que comprova que existem importantes negócios realizados pela trading fora do grupo, atendendo pequenas e médias empresas ou mesmo outros grupos financeiros. $E$ interessante notar, por exemplo, que foi a Sumitomo Shoji (trading do grupo Sumitomo) que vendeu à Indonésia uma usina de energia térmica construída pela Mitsubishi.

Em recente estudo sobre exportação, as características das tradings firms foram resumidas nos seguintes termos:

a) controlam uma grande parte do mercado japonês;

R. Serv. públ., Brasília, 109 (1) jan./mar. 1974 
b) estão presentes, por filiais ou representantes, em todos os países do mundo;

c) negociam com qualquer tipo de produto;

d) têm facilidades especiais para negociar com o seu próprio grupo;

e) podem ultrapassar as rivalidades entre grupos para negociar com empresas de outro conglomerado;

f) têm uma rede comercial e capital para realizar qualquer tipo de negócio no Japão e no exterior.

Houve quem pensasse que, com a industrialização do Japão, as tradings firms se tornassem um anacronismo, mas foi exatamente o contrário que aconteceu, pois elas se reciclaram para atender às necessidades da economia. Acompanharam, mediante uma adequada departamentalização, a mudança da estrutura industrial do país. Após terem montado uma rede mundial de negócios, condicionaram a produção nacional para atender às necessidades do marketing quando não modificaram as condições existentes no exterior, a fim de garantir o escoamento da produção japonesa. A sua flexibilidade e rapidez de atuação tem permitido a realização de grandes operações comerciais que foram mais difíceis ou até impossíveis para países que não contavam com tais instrumentos. Assim, se afirmou que os movimentos das tradings companies são parecidos com o círculo exterior de uma roda, mais rápido e centrífugo, enquanto os fabricantes fazem movimentos mais lentos e centrípetos. Essa flexibilidade e o poder de adaptação às circunstâncias no tempo e no espaço permitiram que as tradings realizassem importantes operaç̃oses com os Estados Unidos, com a União Soviética, com os países da América Latina e da África. Assim, importam madeira da União Soviética e fornecem-lhe máquinas. Utilizam a Coréia e Taiwan como grandes parques industriais produtores. Sendo a indústria têxtil de Taiwan superior à da Coréia na técnica de fiação, enquanto a Coréia é mais eficiente na costura e no corte, as tradings companies produzem fios, linhas e roupas em Taiwan e terminam-nos na Coréia para exportá-los para outros países. Verificamos, pois, que elas aproveitam as facilidades de comunicação e transporte para, ultrapassando as ideologias, realizar o sonho de Wendell Willkie no seu livro "Um Mundo Só" (One world), aproximando as naÇões e intensificando o comércio internacional. Essa função das tradings assume maior importância no momento em que os países, em via de desenvolvimento, querem intensificar o seu comércio 
internacional em vez de receber auxílios dos demais Estados, conforme a fórmula consagrada "Trade; not aid".

Trabalhando com comissões relativamente baixas, cientes da sua responsabilidade social e econômica no desenvolvimento do país, as tradings companies tornaram-se no Japão as catalizadoras naturais dos negócios, as criadoras dos grandes corredores nacionais e internacionais do comércio, permitindo a introdução e a renovação do know how, a redução dos custos operacionais e a realização de uma verdadeira reorganização industrial para dar às empresas a necessária competitividade no mercado externo. Num mundo em que a vida apresenta uma complexidade crescen. te e exige uma especialização progressiva, a trading company pô. de fornecer ao Japão um instrumento flexível e hábil para a re. novação do seu parque industrial e a conquista de novos merca. dos, garantindo assim o enriquecimento do país e o seu desenvolvimento econômico. Trata-se de um exemplo que o Brasil não pode desprezar e que a nossa legislação já consagra e incentiva como uma técnica adequada de aceleração do desenvolvimento econômico. 